\title{
Omega-3 Consumption Assessment in Vegetarian Diets.
}

\author{
Carolina V. M. B. Pimentel ${ }^{1 *}$, Viviane L. Simomura ${ }^{2}$ Leticia Kitzinger $^{3}$ \\ ${ }^{1}$ Faculty of Public Health of the University of São Paulo, São Paulo, SP - Brazil; Paulista University, São Paulo, \\ SP - Brazil. \\ ${ }^{2}$ Universidade Comunitária da Região de Chapecó - UNOCHAPECO, Chapecó, SC - Brazil. \\ ${ }^{3}$ Universidade Paulista, São Paulo, SP - Brazil. \\ *Corresponding author: Carolina Vieira de Mello Barros Pimentel, Faculty of Public Health of the University of São Paulo, São Paulo, SP - \\ Brazil; Paulista University, São Paulo, SP - Brazil. \\ Received date: December 03, 2019; Accepted date: December 24, 2019; published date: January 06,2020 \\ Citation: Carolina V. M. B. Pimentel., Viviane L. Simomura., Kitzinger L. (2020) Omega-3 Consumption Assessment in Vegetarian Diets. J \\ Clinical Cardiology and Cardiovascular Interventions, 3(3); DOI:10.31579/2641-0419/033 \\ Copyright: (c) 2020 Carolina Vieira de Mello Barros Pimentel. This is an open access article distributed under the Creative Commons \\ Attribution License, which permits unrestricted use, distribution, and reproduction in any medium, provided the original work is properly cited.

Abstract
Understanding feeding consumption and nutrient ingestion in vegetarian diet is essential to foster nutritional adequacy. The
goal was assessing Omega-3 consumption in such diets. It is a transversal study, performed with 09 vegetarian adults. The
ingestion was achieved by means of 24 -Hour Reminder and the nutrients were defined by nutritional software. The results
disclosed that the diet is rich in ALA (alpha-linolenic acid), however the functions are performed by EPA (eicosapentaenoic
acid) and DHA (docosahexaenoic acid). ALA is capable of converting inefficiently in the other ones. In the present study,
ALA consumption is above DRI's (2.55g \pm 2.14$)$, but when it is converted to EPA (326mg) and DHA (65.5mg) is below
EFSA guidance and North American cardiovascular disease prevention and treatment guidelines. It was possible to
conclude that this nutrient is essential to health, and in vegetarian diet, it is not achieved, a special care is required in diet
planning.
Keywords: vegetarian diet; omega-3; consumption; nutrients.

\section{Abbreviations:}

ALA: alpha-linolenic acid

EPA: eicosa pentaenoic acid

DHA: docosa hexaenoic acid

\section{Introduction}

Relevant studies have suggested that adopting vegetarian diets is associated to mortality decrease concerning all causes and specific causes, including cardiovascular, renal and endocrine [1]. Vegetarians have a $32 \%$ lower death risk due to heart ischemic disease [2], and $18 \%$ decrease in general cancer incidence when compared to non-vegetarian [3].

Despite the evidence supporting vegetarian diet benefits, it is important that it is properly planned and nutritionally adequate, in order to prevent deficiencies [4]. Nutrient ingestion average data are used to characterize and check consumption difference between vegetarians and nonvegetarians and nutritional adequacy is performed by means of comparing habitual ingestion to Estimated Average Requirements (EAR). Data achieved through such analyses are capable of describing inadequate ingestion prevalence or risk existence [5].

Due to high ingestion of fruits, legumes and vegetables, average ingestion of fibers, vitamin $\mathrm{A}, \mathrm{C}$ and $\mathrm{E}$, thiamine, riboflavin, folate, calcium, magnesium and iron is higher among vegetarians compared to nonvegetarians, although both groups present consumption below recommended to magnesium and vitamins $\mathrm{A}$ and $\mathrm{E}$ [6].

Calcium, iron and zinc minerals, described as critical in vegetarian diets, also achieved higher consumption among vegetarians. However, it is necessary to understand such nutrient bioavailability according to feeding matrix to define quality and better seizing by the organism. Iron, for instance, is ingested in non-heme form in such diets, that has absorption hindered compared to its heme fraction [7].

The same happens to Omega-3 fatty acids. Vegetable origin foods are rich in alpha-linolenic acid (ALA), that has 18 carbons, and animal origin foods, especially fish, are rich in eicosapentaenoic acid (EPA) and docosahexaenoic acid (DHA), with 20 or more carbons. Thus, EPA and DHA ingestion is practically null in vegetarians [8]. Rizzo et al. (2013) showed that DHA average ingestion in 2,000 kcal diets was $102 \mathrm{mg}$ in omnivorous, $98.4 \mathrm{mg}$ in pesco-vegetarians, while vegetarians and vegans presented ingestion equal to 0 [9].

EPA and DHA have important functions in the organism due to the fact they are incorporated in cellular membranes, providing flexibility to them. It also plays an essential role in anti-inflammatory process, in adequate fetal development and in healthy aging, and they also perform as lipid metabolites, and they are, thus, considered beneficial to prevent and treat several cardiovascular diseases associated to dyslipidemias. DHA is also found abundantly in brain and retina, what provides to this nutrient a relevant function in cognitive and ocular health [10].

ALA works as EPA and DHA precursor, and it can be converted by means of several desaturation stages. However, this process efficiency is very low in adult humans and depends on factors including ALA quantity present in the diet, and also, linoleic acid ingestion (AL) [11]. It is suggested that the ALA percentage rate to EPA is only 8 to $12 \%$, and to DHA, this conversion decreases even further, reaching, in average, $1 \%$ [12].

In this context, despite being considered beneficial to cardiac health, vegetarian diet can also be associated to cardiovascular risk factors. Cardioprotective quality offered by vegetarian diets can be attenuated in some nutrients, including vitamin D, vitamin B12 and Omega-3. It is believed that low tissue concentrations of long- chain polyunsaturated 
J Clinical Cardiology and Cardiovascular Interventions 2

fatty acids can counterbalance atheroprotective effects in coronary disease mortality general risk sum [13]. The aims of this study were to evaluate omega 3 consumption and to apply ALA conversion rates for EPA and DHA fractions in vegetarian diets.

\section{Materials and Methods}

It is a transversal study, where the sampling was comprised by vegetarian or vegan individuals invited to participate of the research, by electronic means. The participants were serviced in a Health School Clinic, on May $6^{\text {th }}, 7^{\text {th }}$ and $14^{\text {th }}, 2019$, and signed the Free Informed Term of Consent (FITC).

\section{Data Collection}

The data collection has been formed by research guidance, FITC enforcement, circumference measurement of wrist, waist and hip and research instrument enforcement.

The research instrument included an anamnesis questionnaire (Appendix 3 ) and 24-hour reminder (Appendix 4). In order to assess the measures, stadiometer of the brand Alturaexata ${ }^{\circledR}$, Welmy $\AA$ scale and Trader ${ }^{\circledR}$ measuring tape.

\section{Inclusion and Exclusion Factors}

The inclusion factors were: vegetarian and vegan individuals, over 18 years old and the ones that were not within the age range were excluded, as well as the ones that did not sign the Free Informed Term of Consent.

\section{Tab and Statistical Analysis}

The data found were tabbed in Excel and the consumption analysis was performed by means of Canadian Nutrient File database to Omega fractions and DietPro ${ }^{\circledR}$ nutrition software to other nutrients. The data achieved were processed in statistical analysis software SPSS ${ }^{\circledR}$ version 18.0 to achieve the results.

\section{Consumption Comparison, Guidance and Nutritional Classification}

In order to compare consumption with ingestion guidance, Dietary Reference Intakes (DRIs) and European Food Safety Authority (EFSA) guidance were used. BMI and cardiovascular risk classification was performed by means of parameters provided by WHO (1997 and 2004).

\section{References}

Reference survey of Omega-3 consumption benefits, population consumption and conversion mechanism was performed by means of papers published in databases Scielo, Pubmed and Lilacs. Inclusion criteria were articles performed with adult and elderly population in English or Portuguese language and exclusion criteria were papers published in other languages.

\section{Ethics Committee}

The present study was submitted to Research Ethics Committee of Universidade Paulista as part of a research project of several topics on nutrition and vegetarianism, named "Vegetarian diet influence in the health of adults in the city of São Paulo" and it was approved on 04/26/2019, with opinion number 3.287.700

\section{Results and Discussion}

General Data, Anthropometry and Nutritional Consumption The sample was comprised by 9 women and all considered themselves ovo-lacto vegetarian, i.e., they consume eggs, milk and byproducts, however they exclude all kinds of meats from their diets. The prevalent education level was complete higher education, represented by $77.8 \%$ of women interviewed. Average BMI was $21.98 \mathrm{~kg} / \mathrm{m}^{2}$, average waist circumference was $75.7 \mathrm{~cm}$, and average waist-hip ratio was $0.79 \mathrm{~cm}$. Such values rate the group as adequate weight (BMI from 18.5 and 24.9 $\left.\mathrm{kg} / \mathrm{m}^{2}\right)$ and without risk to cardiovascular disease development $(\mathrm{CC}<80$ cm and RCQ < 0.8), according to WHO, 1997 and 2004. No participant declared to have diabetes, arterial hypertension or dyslipidemia. The studied population anthropometric data can be seen in (Table 1).

\begin{tabular}{|c|c|c|}
\hline Variable & Average & Standard deviation \\
\hline Age $($ years $)$ & 31.6 & \pm 9.6 \\
\hline BMI $\left(\mathrm{kg} / \mathrm{m}^{2}\right)$ & 21.98 & \pm 3.2 \\
\hline CC $(\mathrm{cm})$ & 75.7 & \pm 7.4 \\
\hline Waist-hip ratio & 0.79 & \pm 0.4 \\
\hline
\end{tabular}

Table 1: Anthropometric data

The data present in the literature reinforce that the vegetarian diet tends to foster lower overweight and obesity risks, and lower cardiovascular risk. Controlled and random study systematic review and meta-analysis stated that the individuals that adopted the vegetarian diet had, in average, $0.74 \mathrm{~kg} / \mathrm{m}^{2}$ less than omnivorous, as well as less waist circumference, which was, in average, $2.86 \mathrm{~cm}$ smaller in vegetarians [14].

ALA average consumption was $2.25 \mathrm{~g}$, of EPA $0.02 \mathrm{~g}$, and DHA $0.04 \mathrm{~g}$, and $\mathrm{AL}$ consumption was $11.82 \mathrm{~g}$, standing for the largest share of polyunsaturated fatty acids consumed (total of $18.76 \mathrm{~g}$ ). The consumption of these and other nutrients can be seen in (Table 2).

\begin{tabular}{|l|l|l|}
\hline Variable & Average & Standard deviation \\
\hline Energy (Kcal) & 2193.81 & \pm 824.41 \\
\hline Carbohydrates (g) & 280.38 & \pm 105.85 \\
\hline Fibers (g) & 38.16 & \pm 19.55 \\
\hline Proteins (g) & 76.69 & \pm 36.65 \\
\hline Total fats (g) & 89.97 & \pm 47.13 \\
\hline Saturated fat (g) & 11.88 & \pm 6.54 \\
\hline Monounsaturated fats (g) & 22.19 & \pm 14.85 \\
\hline Polyunsaturated fats (g) & 18.76 & \pm 13.64 \\
\hline AL (g) & 11.82 & \pm 8.75 \\
\hline ALA (g) & 2.55 & \pm 2.14 \\
\hline EPA (g) & 0.02 & \pm 0.04 \\
\hline DHA (g) & 0.04 & \pm 0.06 \\
\hline Cholesterol (mg) & 298.40 & \pm 338.44 \\
\hline Vitamin B12 (mcg) & 0.71 & \pm 0.68 \\
\hline Calcium (mg) & 902.68 & \pm 398.76 \\
\hline Iron (mg) & 25.19 & \pm 8.80 \\
\hline Zinc (mg) & 6.52 & \pm 3.55 \\
\hline
\end{tabular}

Table 2: Average nutrient consumption in this study

There are few available studies in the literature, in English or Portuguese language, that analyze lipid consumption profile, considering the single value of polyunsaturated fatty acids and field works that apply ALA conversion to EPA or DHA were not identified in field works.

Mann et al. (2006) showed that omnivorous consumption of ALA, EPA and DHA was, correspondingly, $1.96 \mathrm{~g} /$ day, $0.07 \mathrm{~g} /$ day and $0.12 \mathrm{~g} /$ day. For ovo-lacto vegetarians, it was $1.42 \mathrm{~g} /$ day to ALA, null to EPA and $0.01 \mathrm{~g} /$ day of DHA. Vegans consumed $1.15 \mathrm{~g}$ /day of ALA and ingestion was null to EPA and DHA [15].

Welch et al (2010) assess fraction consumption of Omega-3 and AL in 
omnivorous and vegetarians that participated of cohort EPIC-Norfolk and the results in vegetarian women disclosed that the ingestion was $10.06 \mathrm{~g} /$ day of AL, $0.97 \mathrm{~g} /$ day of ALA, $0.01 \mathrm{~g} /$ day of EPA and $0.0004 \mathrm{~g} / \mathrm{day}$ of DHA [16].

Although the found results show quantitative differences when compared to the literature, it is possible to observe that the consumption pattern, higher to AL and ALA, and lower to EPA and DHA, were kept in every study.

In a nutritional quality comparison between vegan, vegetarian, semivegetarian, pesco-vegetarian and omnivorous diet, Clarys et al. (2014) found out that polyunsaturated fatty acid consumption was higher among vegans (28g) and lower among omnivorous (22g). Vegetarians consumed, in average, $24 \mathrm{~g}$ [17]. Moreover, it is not possible to state how much was the actual specific ingestion of each polyunsaturated fatty acid type, as there was no division among Omega-3, Omega-6, or their fractions.

Likewise, a review work of the two most important cohorts with nutritional consumption in vegetarians, EPIC-Oxford and Adventist Health Study-2 (AHS-2), performed by Segovia-Siapco \& Sabaté (2018), corroborated with previous findings, restating a higher polyunsaturated fatty acids and a lower consumption of saturated fatty acids in vegetarian and vegan diet when compared to omnivorous one [18].

Elorinne et al. (2016), although fatty acid fractions at consumption level are not considered, they report that, as they assessed that plasmatic ALA average was higher in vegans than $(1.28 \%)$ in omnivorous $(0.78 \%)$, as for DHA, this ratio was inverted, and $0.85 \%$ to the first group, to the first group, compared to $2.25 \%$ in the second [19].

As they assessed fatty acid consumption biomarkers by participants of AHS-2, Miles et al. (2019) found out that $21.7 \%$ of the fats that comprise ovo-lacto vegetarian adipose tissue is originated from AL, $1.24 \%$ from ALA, $0.02 \%$ from EPA and $0.12 \%$ from DHA. For omnivorous, such values are, correspondingly, $19.1 \%, 1.03 \%, 0.03 \%$ and $0.18 \%$ [20]. Such data show that, indeed, vegetarians consume larger ALA fraction quantities, while omnivorous consume larger EPA and DHA fraction quantities.

\section{Conversion to EPA and DHA}

Despite the low EPA and DHA consumption by vegetarian and vegan individuals, they present in their serum concentrations and in adipose tissue, percentage rates of such Omega- 3 fractions. That takes places as the organism is capable of converting ALA in the other fractions.

ALA has high absorption. In a study, 100g of linseed oil to patients with ileostomy, and the authors verified there was $98 \%$ of ALA absorption, similar value to AL absorption. Polyunsaturated fatty acids are absorbed in the intestine, and then introduced to blood circulation can be incorporated to cellular membranes, energy reserves, like, for instance, in adipose tissue, participate of energy production, or in the case of ALA and AL, undergo conversion process to larger chain fatty acids [12,21].

It is believed that this conversion takes place, mainly, in the liver, although there are some evidences of a high enzyme encoding gene expression that participate of this metabolic pathway in the brain, retina and testicles, when compared to other tissues. ALA and AL chain desaturation and stretching processes take place in endoplasmatic reticulum, except for the last beta-oxidation, that will originate the DHA that takes place in the peroxisome [12]

There is a competition between ALA and AL through metabolic pathway to convert such fatty acids in others, of larger chains. While ALA is converted in EPA and DHA, AL is converted in arachidonic acid (AA). Enzyme delta 6 desaturase (D6D) is the first one to participate of the pathway and it is believed to be the responsible for the reaction limitation, as it is responsible for two fatty acid molecule desaturation, and despite the fact there is a preference for ALA, the quantity of AL provided to conversion is much larger, building excess $[12,22]$.

D6D action result on ALA is forming eicosatetraenoic acid, which is converted in EPA by action of enzyme Delta 5 Desaturase (D5D) that also acts in Omega-6 metabolic pathway, being responsible for its end stage, generating AA. Upon EPA conversion, the same initial stage, D6D, acts in desaturation of this Omega-3 fraction, generating, finally, DHA [12]. A conversion stage scheme can be seen in (Figure 1) [23]. 
$n-6$

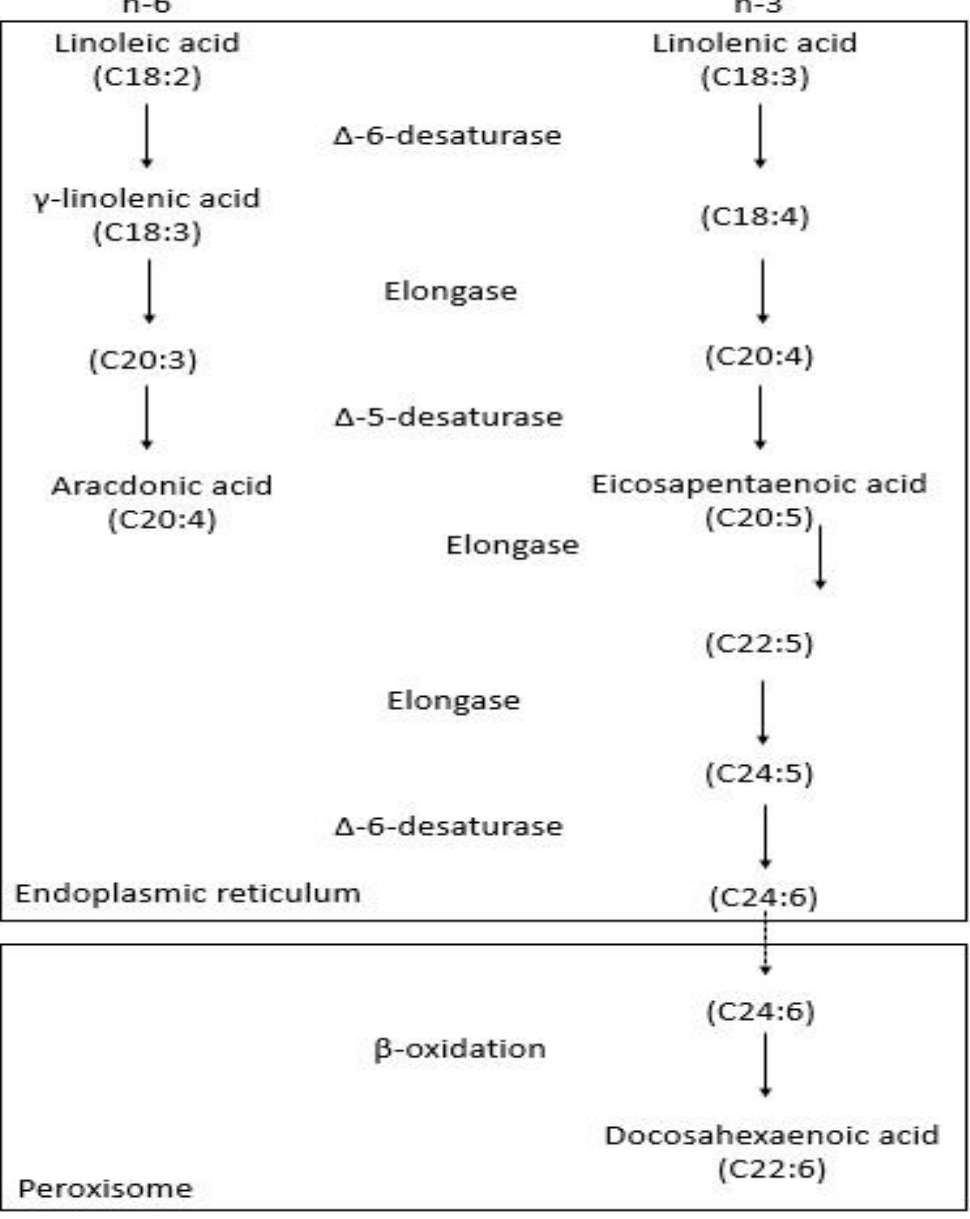

Figure 1: Conversion metabolic pathways of Omegas 3 and 6. Translated and adapted from Appolinário et al., 2011 Genetics is also capable of influencing in ALA and AL conversion, as individuals with D6D deficiency are not capable of synthesizing EPA, DHA or AA, from fractions containing 18 carbons [22].

Omega-3 Ingestion Consumption and Benefit Guidance

Omega-3 ingestion guidance is performed by Institute of Medicine (IOM, 2005) by means of ALA and the value recommended to women from 14 years of age is $1.1 \mathrm{~g} /$ day [24].This value, by applying average conversion rate of $1 \%$ is translated into $11 \mathrm{mg}$ of DHA a day.

On the other hand, European Food Safety Authority (EFSA) published in 2012 a scientific opinion on EPA and DHA consumption. In the document, the consumption guidance to such two nutrients in adults is around 250 to $>600 \mathrm{mg} /$ day for health benefit purposes. The guidance recommends that DHA consumption alone is at least $250 \mathrm{mg} /$ day [25].

The same document stated that the supplementation combined of EPA and DHA in doses above $5 \mathrm{~g} /$ day, or EPA isolated above $1.8 \mathrm{~g} / \mathrm{day}$, or yet DHA isolated around $1 \mathrm{~g}$ /day does not raise safety concerns to human health. EPA and DHA consumption in combined way between 2 and $6 \mathrm{~g}$ /day and DHA between 2 and $4 \mathrm{~g}$ /day is capable of increasing serum concentration of LDL cholesterol around 3\%, what does not provide effect in healthy population cardiovascular risk. Moreover, 1g/day consumption of EPA and DHA alone or combined have a series of positive closures to cardiovascular, neurological and immunological health [25].

The Scientific Committee of American Heart Association (AHA) recommends there is fish consumption at least twice a week or consumption of $500 \mathrm{mg} /$ day of Omega-3 long-chain polyunsaturated fatty acids (LCPUFA) to prevent and decrease cardiovascular disease risk [26] LCPUFAs, i.e., the ones that have 20 carbon atoms or more in their chains, are eicosanoid precursors, comprised of prostaglandins and thromboxanes, and thus, they play a relevant role in immunological and neurotransmitter system regulation, as well as in cholesterol metabolism, and especially DHA, in phospholipid membrane of brain and retina cells [27]

A meta-analysis showed that Omega-3 PUFA consumption and circulating levels are significantly associated to mortality risk decrease due to all causes in general population, and the associations are similar to EPA and DHA [28].

EPA and DHA supplementation also has beneficial effects during pregnancy. Such nutrients are associated to premature delivery risk decrease [29], supplemented mothers presented lower inflammatory marker levels [30] and 16-year old teenagers, kids of supplemented mothers during pregnancy, have lower asthma incidence [31].

Although there is controversial information yet, there is evidence that DHA consumption has a promising function in neurological and cognitive development, and protective function in neurological degeneration, and prevents neuropsychiatric diseases, including psychosis, bipolar affective disorder and stress [32].

Omega-3 deficiency consequences in humans are not totally know yet, however, this nutrient deficiency was observed in Alzheimer disease carriers. Clinical assays performed in rats associated low Omega-3 ingestion to cognitive vulnerability increase and memory decrease [33]

\section{ALA conversion rate application to EPA and DHA}

ALA average consumption is higher that IOM guidance (2005), and considering the ingestion of $2.55 \mathrm{~g}$ of ALA by the women that participated of this study and the conversion limits of $12 \%$ to EPA and $1 \%$ to DHA, such nutrient total consumption simulation is $391.5 \mathrm{mg} /$ day, as can be seen in (Table 3). 


\begin{tabular}{|c|l|l|}
\hline Nutrient & Average ingestion & Conversion \\
\hline ALA - EPA (mg) (12\%) & 2550 (ALA) & 306 \\
\hline EPA (mg) & 20 & - \\
\hline Total EPA (mg) & - & 326 \\
\hline ALA - DHA (mg) (1\%) & 2550 (ALA) & 25.5 \\
\hline DHA (mg) & 40 & - \\
\hline TOTAL DHA (mg) & - & 65.5 \\
\hline Total LCPUFA (mg) & - & 391.5 \\
\hline
\end{tabular}

Table 3: EPA and DHA consumption simulation considering nutrient average ingestion in this study and conversions
This value is within EFSA guidance (2012) of $250 \mathrm{mg}$ to $>600 \mathrm{mg}$ a day of associated EPA and DHA. However, the same authority, it recommends that DHA consumption in isolated fashion is, at least, $250 \mathrm{mg}$, and when compared to average consumption result with conversion rate application $(65.5 \mathrm{mg})$, the value reaches only $26.2 \%$ of adequacy.

Another relevant point is that AHA recommends associated EPA and DHA consumption, in, at least, $500 \mathrm{mg} /$ day to decrease the cardiovascular risk, a value that places consumption adequacy in 78.3\%. In (graph 1), it is possible to see the gaps between Omega-3 fraction ingestion and guidance.

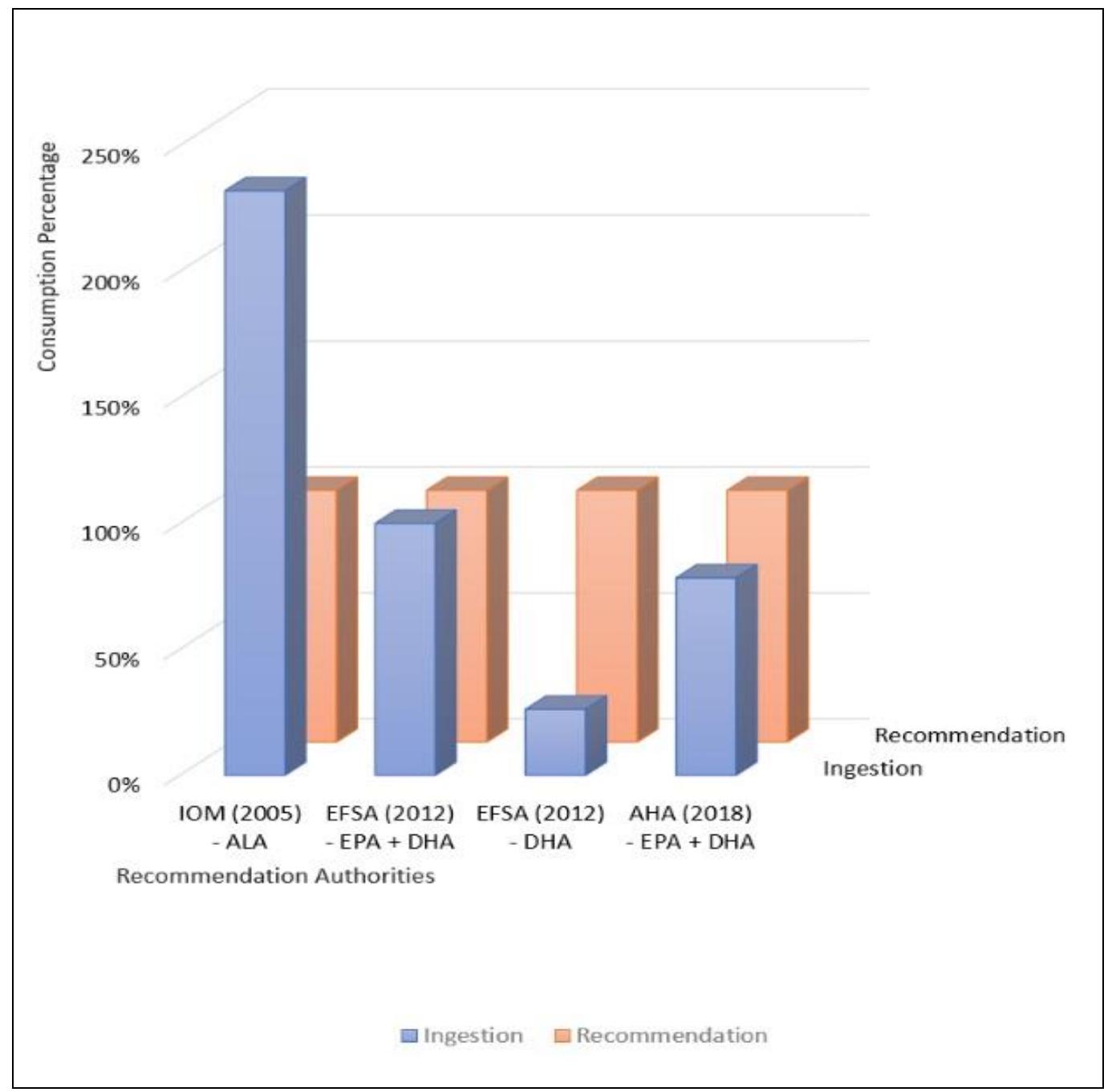

Graph 1: Adequacy percentage rates between Omega-3 fraction consumption in this study and recommendation

It is worth noting that, in the present study, maximum conversion values were used, however, as discussed above, this value can be even lower, considering higher $\mathrm{AL}$ ingestion, that competes through conversion metabolic pathway, besides genetic factors.

\section{Possible Solutions to Vegetarian and Vegan Population}

The first potential solution to correct such gaps is fostering the vegetarian population to increase ALA source ingestion to increase conversion, and thus, suiting the consumption. One of the best options is using linseed oil, which, according to Canadian Food Nutrition, has around 5.33g of ALA in $1 \mathrm{ml}$, while the same quantity converted in grams, that translates into $0.9 \mathrm{~g}$ of linseed, has $2.05 \mathrm{~g}$ of the same nutrient. It is important to note that this alternative increases the caloric intake of the diet and is not a viable option in energy restriction strategies.

This conduct is already discussed in the literature that acknowledges the challenge of EPA and DHA plasmatic levels in vegetarians and vegans. Harris, 2014 approaches this discussion and suggests that ALA consumption increase is capable of raising LCPUFA serum 
concentrations in this population [34].

A relevant question in this solution is that ALA-source vegetable foods are also linoleic acid source (LA), one type of Omega-6, what would still prevent the conversion optimization. Moreover, the toxicity harms caused by Omega- 6 high ingestion are also known in the literature as inflammation progression, asthma, some cancer types and worsening of several disorders including depression, anxiety, allergies, obesity, diabetes, hypertension, irritable bowel syndrome, among others. In addition, it is suggested that a diet with omega- 6 amounts greater than $50 \%$ of omega- 3 is associated with deaths from thrombotic causes [35]. Nevertheless, it is possible to perform balance correction by means of diet. Each food has a balance score between Omegas, according to their content in relation to such nutrients. More than 5000 indexes have been defined by USDA Nutrient Database, a database created by the United States Agriculture Department with food nutritional information [36], and then apps validated and available on the Internet were created, providing the score of a specific food and its effect in health [37].

Another possible alternative to correct DHA consumption in vegetarian diets is using microalgal based DHA supplements. A systematic review, published in 2017, including four random studies and two prospective cohorts, and the result was that the studies included showed increase in serum, plasmatic and platelet fractions of DHA after its consumption by means of alga supplements [38].

\section{References}

1. Orlich MJ, Singh PN, Sabaté J, et al. (2013) Vegetarian dietary patterns and mortality in Adventist Health Study 2. JAMA Intern Med

2. Crowe FL, Appleby PN, Travis RC, Key TJ. (2013) Risk of hospitalization or death from ischemic heart disease among British vegetarians and non-vegetarians: results from the EPIC-Oxford cohort study. The American Journal of Clinical Nutrition,

3. Huang, T., Yang, B., Zheng, J., Li, G., Wahlqvist, M. L. (2012) Cardiovascular Disease Mortality and Cancer Incidence in Vegetarians: A Meta-Analysis and Systematic Review. Annals of Nutrition and Metabolism,

4. Parecer Técnico CRN-3 No 11/2015 Vegetarianismo Conselho Regional de Nutricionistas $-3^{\text {a }}$ região (SP-MS), 2015. Available on:

5. Farmer B (2014) Nutritional adequacy of plant-based diets for weight management: observations from the NHANES13. The American Journal of Clinical Nutrition,

6. Farmer, B., Larson, B. T., Fulgoni, V. L., Rainville, A. J., \& Liepa, G. U. A (2011) Vegetarian Dietary Pattern as a Nutrient-Dense Approach to Weight Management: An Analysis of the National Health and Nutrition Examination Survey 1999-2004. Journal of the American Dietetic Association,

7. Deriemaeker, P., Alewaeters, K., Hebbelinck, M., Lefevre, J., Philippaerts, R., \& Clarys, P. (2010) Nutritional Status of Flemish Vegetarians Compared with Non-Vegetarians: A Matched Samples Study. Nutrients,

8. Burdge, G. C., Tan, S.-Y., \& Henry, C. J. (2017) Long-chain n-3 PUFA in vegetarian women: a metabolic perspective. Journal of Nutritional Science,

9. Rizzo, N. S., Jaceldo-Siegl, K., Sabate, J., \& Fraser, G. E. (2013) Nutrient Profiles of Vegetarian and Nonvegetarian Dietary Patterns. Journal of the Academy of Nutrition and Dietetics,

10. Swanson, D., Block, R., \& Mousa, S. A. (2012) Omega-3 Fatty Acids EPA and DHA: Health Benefits Throughout Life. Advances in Nutrition,
11. Greupner, T., Kutzner, L., Pagenkopf, S., Kohrs, H., Hahn, A. et al. (2018) Effects of a low and a high dietary LA/ALA ratio on long-chain PUFA concentrations in red blood cells. Food \& Function,

12. Baker, E. J., Miles, E. A., Burdge, G. C., Yaqoob, P., \& Calder, P. C. (2016) Metabolism and functional effects of plant-derived omega-3 fatty acids in humans. Progress in Lipid Research,

13. Hall, W. L. (2017) The future for long chain n-3 PUFA in the prevention of coronary heart disease: do we need to target non-fish-eaters? Proceedings of the Nutrition Society,

14. Viguiliouk, E., Kendall, C. W., Kahleová, H., Rahelić, D., Salas-Salvadó. et al. (2018). Effect of vegetarian dietary patterns on cardiometabolic risk factors in diabetes: A systematic review and meta-analysis of randomized controlled trials. Clinical Nutrition.

15. Mann, N., Pirotta, Y., O'Connell, S., Li, D., Kelly, F., \& Sinclair, A. (2006) Fatty acid composition of habitual omnivore and vegetarian diets. Lipids, 41(7), 637-646.

16. Welch, A. A., Shakya-Shrestha, S., Lentjes, M. A., Wareham, N. J., \& Khaw, K.-T. (2010). Dietary intake and status of $n-3$ polyunsaturated fatty acids in a population of fish-eating and non-fish-eating meat-eaters, vegetarians, and vegans and the precursor-product ratio of $\alpha$-linolenic acid to long-chain $n-3$ polyunsaturated fatty acids: results from the EPIC-Norfolk cohort. The American Journal of Clinical Nutrition, 92(5), 1040-1051.

17. Clarys, P., Deliens, T., Huybrechts, I., Deriemaeker, P., Vanaelst, B., et al. (2014) Comparison of Nutritional Quality of the Vegan, Vegetarian, Semi-Vegetarian, PescoVegetarian and Omnivorous Diet. Lipids, 6(3), 1318-1332.

18. Segovia-Siapco, G., \& Sabaté, J. (2018). Health and sustainability outcomes of vegetarian dietary patterns: a revisit of the EPIC-Oxford and the Adventist Health Study-2 cohorts. European Journal of Clinical Nutrition.

19. Elorinne, A.-L., Alfthan, G., Erlund, I., Kivimäki, H., Paju, A. (2016) Food and Nutrient Intake and Nutritional Status of Finnish Vegans and Non-Vegetarians. PLOS ONE, 11(2), e0148235.

20. Miles, F. L., Lloren, J. I. C., Haddad, E., Jaceldo-Siegl, K., Knutsen, S., Sabate, J., \& Fraser, G. E. (2019). Plasma, Urine, and Adipose Tissue Biomarkers of Dietary Intake Differ Between Vegetarian and Non-Vegetarian Diet Groups in the Adventist Health Study-2. The Journal of Nutrition.

21. Goyens, P. L., Spilker, M. E., Zock, P. L., Katan, M. B., \& Mensink, R. P. (2006). Conversion of $\alpha$-linolenic acid in humans is influenced by the absolute amounts of $\alpha$-linolenic acid and linoleic acid in the diet and not by their ratio. The American Journal of Clinical Nutrition, 84(1), 44-53.

22. Brenna, J. T., Salem, N., Sinclair, A. J., \& Cunnane, S. C. (2009). $\alpha$-Linolenic acid supplementation and conversion to n-3 long-chain polyunsaturated fatty acids in humans. Prostaglandins, Leukotrienes and Essential Fatty Acids, 80(2-3), 85-91.

23. Appolinário P. P., Derogis P. B. M. C., Yamaguti T. H., Miyamoto S. (2011) Metabolismo, oxidação e implicações biológicas do ácido docosahexaenoico em doenças neurodegenerativas. Quim. Nova, Vol. 34, No. 8, 1409-1416,

24. Institute of Medicine. 2005. Dietary Reference Intakes for Energy, Carbohydrate, Fiber, Fat, Fatty Acids, Cholesterol, Protein, and Amino Acids. Washington, DC: The National Academies Press. 
25. EFSA Panel on Dietetic Products, Nutrition and Allergies (NDA); Scientific Opinion related to the Tolerable Upper Intake Level of eicosapentaenoic acid (EPA), docosahexaenoic acid (DHA) and docosapentaenoic acid (DPA). EFSA Journal 2012;10(7):2815. [48 pp.]

26. Rimm, E. B., Appel, L. J., Chiuve, S. E., Djoussé, L., Engler, M. B. et al. (2018). Seafood Long-Chain n-3 Polyunsaturated Fatty Acids and Cardiovascular Disease: A Science Advisory From the American Heart Association. Circulation, 138(1), e35-e47.

27. Abedi, E., \& Sahari, M. A. (2014) Long-chain polyunsaturated fatty acid sources and evaluation of their nutritional and functional properties. Food Science \& Nutrition, 2(5), 443-463.

28. Chen, G.-C., Yang, J., Eggersdorfer, M., Zhang, W., \& Qin, L.-Q. (2016). N-3 long-chain polyunsaturated fatty acids and risk of all-cause mortality among general populations: a meta-analysis. Scientific Reports, 6(1).

29. Olsen, S. F., Østerdal, M. L., Salvig, J. D., Weber, T., Tabor, A., \& Secher, N. J. (2007). Duration of pregnancy in relation to fish oil supplementation and habitual fish intake: a randomised clinical trial with fish oil. European Journal of Clinical Nutrition, 61(8), 976-985.

30. Krauss-Etschmann S, Hartl D, Rzehak P, Heinrich J, Shadid R. et al. (2008) Decreased cord blood IL-4, IL-13, and CCR4 and increased TGFbeta levels after fish oil supplementation of pregnant women. J Allergy Clin Immunol. 121:464-470 e6.

31. Olsen SF, Osterdal ML, Salvig JD, Mortensen LM, Rytter D. et al. (2008) Fish oil intake compared with olive oil intake in late pregnancy and asthma in the offspring: $16 \mathrm{y}$ of registry- based follow-up from a randomized controlled trial. Am J Clin Nutr. 88:167-175.

32. Bradbury, J. (2011) Docosahexaenoic Acid (DHA): An Ancient Nutrient for the Modern Human Brain. Nutrients, 3(5), 529-554.

33. Pan, Y., Choy, K. H. C., Marriott, P. J., Chai, S. Y., Scanlon, M. J. et al. (2017). Reduced blood-brain barrier expression of fatty acid-binding protein 5 is associated with increased vulnerability of APP/PS1 mice to cognitive deficits from low omega-3 fatty acid diets. Journal of Neurochemistry, 144(1), $81-92$.

34. Harris, W. S. (2014). Achieving optimal n-3 fatty acid status: the vegetarian's challenge... or not. The American Journal of Clinical Nutrition, 100(suppl_1), 449S-452S.

35. Lands, B. (2015). Omega-3 PUFAs Lower the Propensity for Arachidonic Acid Cascade Overreactions. BioMed Research International, 2015, 1-8.

36. Bibus, D., \& Lands, B. (2015). Balancing proportions of competing omega-3 and omega- 6 highly unsaturated fatty acids (HUFA) in tissue lipids. Prostaglandins, Leukotrienes and Essential Fatty Acids (PLEFA), 99, 19-23.

37. Lands, B. (2017) Balancing Omega 3 and 6 Fats Gives Better Health. Essential Fatty. Acids. Website by Bill Lands,

38. Craddock, J. C., Neale, E. P., Probst, Y. C., \& Peoples, G. E. (2017). Algal supplementation of vegetarian eating patterns improves plasma and serum docosahexaenoic acid concentrations and omega-3 indices: a systematic literature review. Journal of Human Nutrition and Dietetics, 30(6), 693-699.
This work is licensed under Creative Commons Attribution 4.0 License

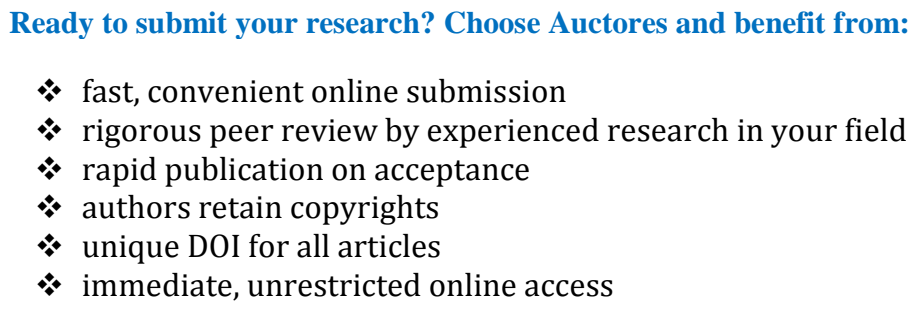

* fast, convenient online submission

* rigorous peer review by experienced research in your field

* rapid publication on acceptance

* authors retain copyrights

* unique DOI for all articles

* immediate, unrestricted online access

At Auctores, research is always in progress.

Learn more www.auctoresonline.org/journals/clinical-cardiology-andcardiovascular-interventions 